OPEN ACCESS

Edited by:

Xingxing Zhang,

Dalarna University, Sweden

Reviewed by:

Yingjie $\mathrm{Xu}$,

Zhejiang University of Technology,

China

Shengchun Liu,

Tianjin University of Commerce, China

*Correspondence:

Enshen Long

esll_09@outlook.com

Specialty section:

This article was submitted to Sustainable Energy Systems and

Policies,

a section of the journal Frontiers in Energy Research

Received: 29 September 2021 Accepted: 23 November 2021

Published: 20 December 2021

Citation:

Zou H, Liu Z and Long E (2021) An Experimental Study on External Ventilation to the Heating Performance of Household Air Source Heat Pump.

Front. Energy Res. 9:785461.

doi: 10.3389/fenrg.2021.785461

\section{An Experimental Study on External Ventilation to the Heating Performance of Household Air Source Heat Pump}

\author{
Hang Zou ${ }^{1}$, Zhanqiang Liu ${ }^{1}$ and Enshen Long ${ }^{2 *}$ \\ ${ }^{1}$ China Construction First Group, Beijing, China, ${ }^{2}$ College of Architecture and Environment, Sichuan University, Chengdu, China
}

The external ventilation conditions have a great influence on the heating performance of the air source heat pump (ASHP) systems. The outdoor units of residential household air source heat pumps are often installed in narrow spaces such as balconies. The ventilation conditions of the outdoor unit will influent the heating performance of the air source heat pump. It is necessary to study the effect of the outdoor unit ventilation conditions on the heating performance of residential household heat pumps. This paper experimentally studied the heating performances of an air source heat pump system with the outdoor unit mounted in a balcony in different external ventilation conditions. The results indicate that the ventilation conditions for the outdoor units have a significant effect on the heating performance of the system. When the inlet of the outdoor unit was close to the sliding door and completely blocked, the ventilation environment was the worst and the coefficient of performance (COP) was the lowest. In addition, the unfavorable ventilation environment could result in a reduction of the COP by $26.2 \%$. When the inlet of the outdoor unit was partially blocked, the heating performance could be improved and the COP was also slightly improved. The great heating performance was obtained under the cross-ventilation condition. This paper can guide the design of the installation position of the household air source heat pump outdoor units in actual engineering.

Keywords: ventilation conditions, air source heat pump, heating performance, coefficient of performance, experimental study

\section{INTRODUCTION}

Reducing building energy consumption and using renewable energy are two important methods to decrease greenhouse gas emissions. Building energy consumption can be reduced by improving the efficiency of HVAC systems. At the same time, the use of heat pumps plays a certain role in achieving energy efficiency (Vocale et al., 2014). Air source heat pumps are widely used to reduce carbon emissions and improve energy efficiency. In China, especially in the southern regions of the Yangtze River, with high outdoor air temperatures and low heating loads, the air source heat pump (ASHP) is widely used in building heating due to its efficient operation and good heating performance in winter (Zhang et al., 2017a).

At present, the research of scholars on ASHP mainly focuses on the application of ASHP in residential and the heating performance of ASHP. Some scholars have considered the use of ASHPs in residential buildings. Kelly et al. (2016) found that displacing oil and solid fuel usage 
with ASHP technology could save household costs, reduce emissions, and have health impacts. Zhang et al. (2017a) proposed and applied high efficiency and environmentfriendly low-temperature ASHP heating systems to meet the demand for clean heating in cold regions of northern China. Jing et al. (2016) analyzed the operating performance of the sensible heat storage ASHP system which is promising and suitable for residential heating in central-south China. Zhang et al. (2017b) established an analytical model of a hybrid heating system and investigated its thermal performance and relationship with climatic parameters. To maximize the overall energy conversion efficiency of such a hybrid heating system, the optimal operation strategy and heating load ratio of each subsystem were established by the inverse problem method. Zhao et al. (2017) considered the influence of the supply and return water temperature of the ASHP on the coefficient of performance (COP), when the ambient temperature remained almost constant. The results showed that the system COP decreased with increasing supply and return water temperatures. Bertsch and Groll (2008) designed and constructed a breadboard system. Then they tested a twostage ASHP for water and air heating, and the two-stage ASHP outperforms most currently available commercial single-stage ASHPs. In summary, research on ASHP heating mainly focuses on heat pump unit performance and composite heat source heating (Busato et al., 2013; Hakkaki-Fard et al., 2014; Redón et al., 2014) and has witnessed many breakthroughs and progress in unit load rate, outdoor temperature, and energy saving potential of multi-energy complementary systems (Zhao et al., 2007; Madonna and Bazzocchi, 2013; Wu et al., 2013; Dongellini et al., 2015).

In addition, some scholars have researched the heating performance of the household ASHP heating system. Li (2015) tested the COP of the system with AHRI 210/240 standard, and the performance data for cooling A tests regarding COP and capacity were used for LCCP calculation. Hewitt and Huang (2008) tested the residential air to water scroll compressor heat pump with an economized R407C vapor injection cycle in a temperature- and humidity-controlled test chamber. Jin et al. (2016) developed and studied an ASHP with an internal heat exchanger (IHX) using R404A as a refrigerant at low ambient temperatures to investigate the effect of ambient temperature on ASHP performance. The IHX technology became more and more effective as the ambient temperature dropped lower and lower. In addition, some scholars have studied methods to improve the heating performance of the ASHP, such as using innovative systems with small temperature difference heat transfer terminals, seeking specific operational strategies, and optimizing unit design (Ge et al., 2011; Touchie and Pressnail, 2014; Vieira et al., 2015). In summary, the heating performance of the ASHP heating system varies under different conditions and outdoor air temperatures. Liu et al. examined the feasibility of the SA-WH in solar shortage regions from a performance perspective and compare its performance to the solar water heater (SWH) and the air-source heat pump water heater (ASHP-WH) (Liu et al., 2020).

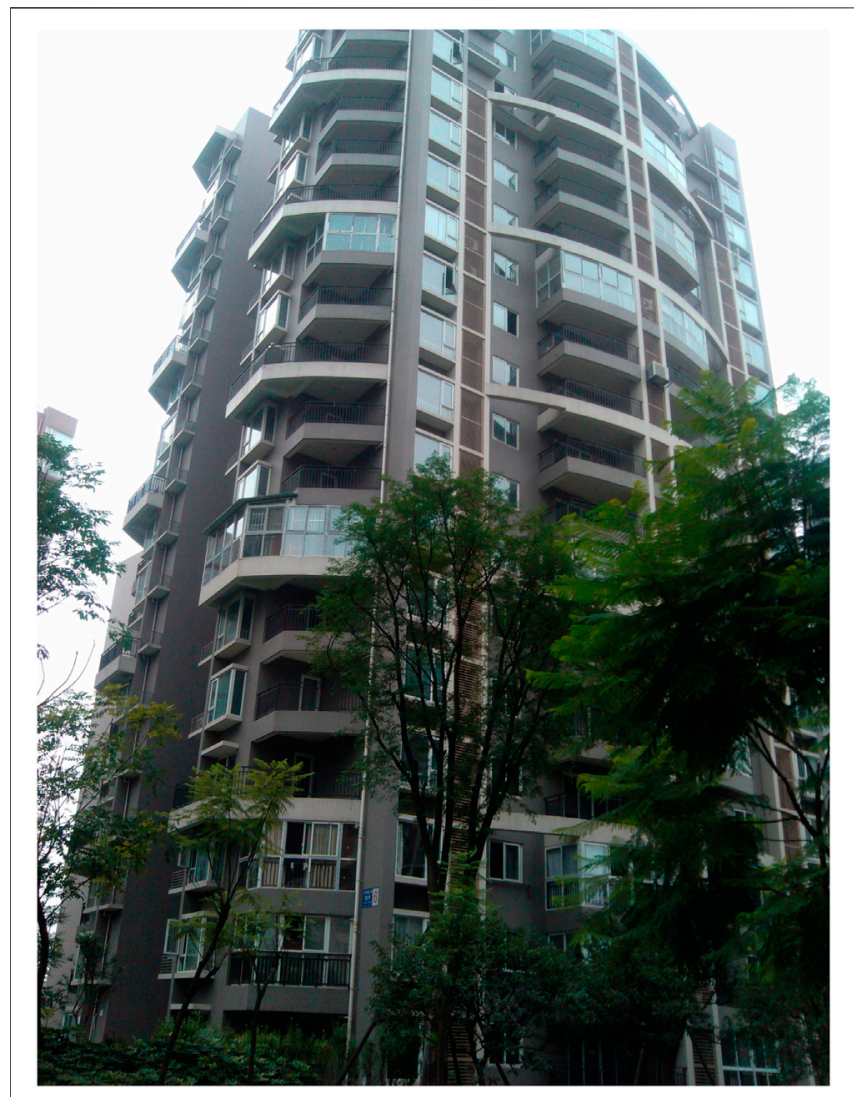

FIGURE 1 | Experimental flat.

The above literature review indicates that the influence of the installation position of the ASHP outdoor unit on its COP was always neglected in the existing studies. It is generally considered that the outdoor unit is placed in an open area where the air inlet and the exhaust are unobstructed according to the specifications so that the COP was measured under the excellent ventilation of the ASHP outdoor unit. However, due to the limited space of residential buildings, the outdoor unit of the ASHP was always installed in narrow spaces in the actual situation. It is difficult to achieve excellent ventilation conditions for the outdoor unit, which would result in a negative effect on the heating performance of an ASHP heating system. To solve this problem, it is necessary to quantitatively study the influence of the ventilation conditions of the ASHP outdoor unit on the heating performance of the heating system. The results can guide the unit reserved space design in the architectural design stage and can be a relatively reasonable arrangement for the outdoor unit installation position in the unit installation stage.

This article is divided into four sections. Introduction, Experimental Set-Up, Results and Discussion, and Conclusion. The novelty of this study is that the heating performance of the household ASHP system in winter was studied under seven conditions in this paper, and the research results can provide guidance to the design of the installation position of the ASHP outdoor unit in actual engineering. 


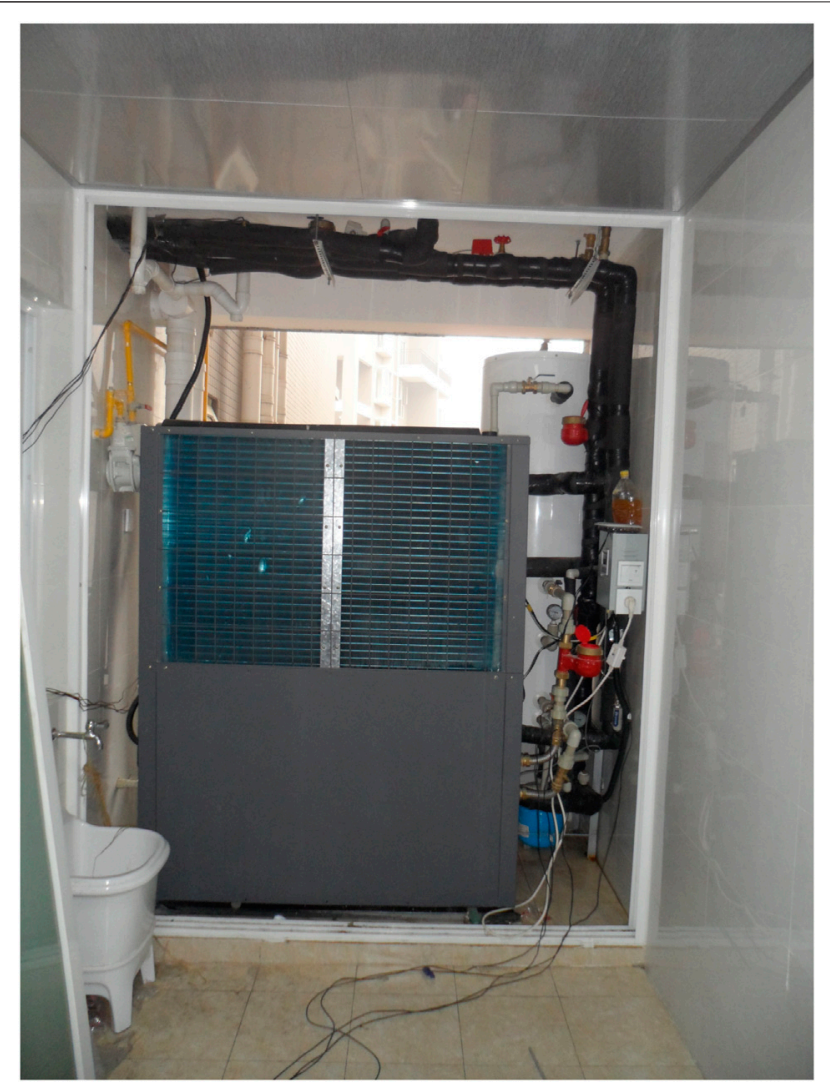

FIGURE 2 | Appearance of air source heat pump

\section{EXPERIMENTAL SET-UP}

\section{Experimental Flat and Installation Position of Air Source Heat Pump Outdoor Unit}

The experimental flat is located in Chengdu City, Sichuan Province. It is situated on the 11th floor of an 18-story residential building, and the area is $140 \mathrm{~m}^{2}$ (Figure 1). The experimental tested system is mounted in the user's home. To satisfy the experimental requirements, the installation position of the ASHP outdoor unit, the domestic hot water tank, the piping system, and the terminal should be reasonably designed to maximize the utilization of the space resources. The outdoor unit and water tank are installed on the balcony. The balcony communicates with the atmosphere, and the guardrail of it is decorated with grilles. Besides, the installation position of the ASHP outdoor unit and hallway are partitioned by installing sliding doors, and the outlet of the outdoor unit faces the outdoor atmosphere, and the inlet faces the sliding doors with $12 \mathrm{~cm}$. The appearance of the ASHP and the test site is shown in Figure 2. The experimental site plan and the installation position of the ASHP outdoor unit are shown in Figure 3.

\section{Experimental Equipment and Instruments}

In this experiment, the heat recovery type ASHP unit, HSLR-T-13

(D) E, is selected as the cold and heat source of the system. It has five working modes, namely: summer refrigeration, refrigeration + hot water, hot water, winter heating, heating + hot water. The size of the host is $1300(\mathrm{~L}) \times 460(\mathrm{~W}) \times 1783(\mathrm{H}) \mathrm{mm}$ and the compressor is a scroll compressor. The rated voltage is $220 \mathrm{~V}$ and the winter heat rating is $15 \mathrm{KW}$ while its rated heating power is $4.65 \mathrm{KW}$. The axial flow fan air volume is $5000 \mathrm{~m}^{3} / \mathrm{h}$ and the air conditioning side pressure loss is $35 \mathrm{KPa}$.

In this experiment, JTRG-II Automatic Test System for Building Thermal Temperature and Heat Flow was adopted to record temperature data, including JTRG-SHENG host for building thermal temperature and heat flow, copper thermocouple and data management software (as shown in Figure 4). To ensure the accuracy of the experimental data, the thermocouples used in the test are compared with each other. The verified thermocouple line temperatures were all within $1^{\circ} \mathrm{C}$, which met the experimental test requirements.

\section{Experimental System}

An ASHP is selected as the heat source and fan coils are selected as the terminal to adjust the indoor thermal environment (Figure 5). In winter, the ASHP produces hot water which the fan coils use to heat the indoor air through convection heat transfer.

\section{Evaluation Index}

COP is used to evaluate the heating performance of the system and is defined by the following equation. The inlet and outlet water temperatures were measured by a thermometer (with the accuracy of $\pm 0.3^{\circ} \mathrm{C}$ ), the flow rate was measured by a water meter (with the accuracy of $\pm 2 \%$ ), and the power consumption was measured by the electricity sensor (with the accuracy of $\pm 2 \%$ ). The thermometers are installed at the water inlet and outlet of the main engine, and the water meter is installed at the water outlet of the main engine.

$$
\mathrm{COP}_{h}=\frac{Q_{h}}{W}=\frac{C \times L \times \Delta T}{W}
$$

where: $Q_{h}=$ heating capacity of the unit $(\mathrm{kW}) ; W=$ machine input power $(\mathrm{kW}) ; C=$ specific heat capacity of water $[4.2 \mathrm{~kJ} /$ $(\mathrm{kg} \cdot \mathrm{K})] ; L=$ water flow $\left(\mathrm{m}^{3} / \mathrm{h}\right) ; \Delta T=$ unit supply water temperature difference $\left({ }^{\circ} \mathrm{C}\right)$.

\section{Experimental Program}

The fan coils in each room operated during the test period. To study the difference of the heating performance under different conditions, the outdoor unit ventilation conditions of the partitioned outdoor space were changed during measurement under the same operating condition of the internal unit. In the experiment, seven conditions were selected by switching the state of the sliding doors and the security door in Figure 2. The seven conditions are listed in Table 1 . In the table, $\sqrt{ }$ indicates the open state while $\times$ indicates the close state. For the first condition, the sliding doors were removed and the security door of the home was fully opened. The test period for each condition is $50-70 \mathrm{~min}$ to avoid excessive changes in the outdoor temperature variations and to better compare the effects of different ventilation conditions. 


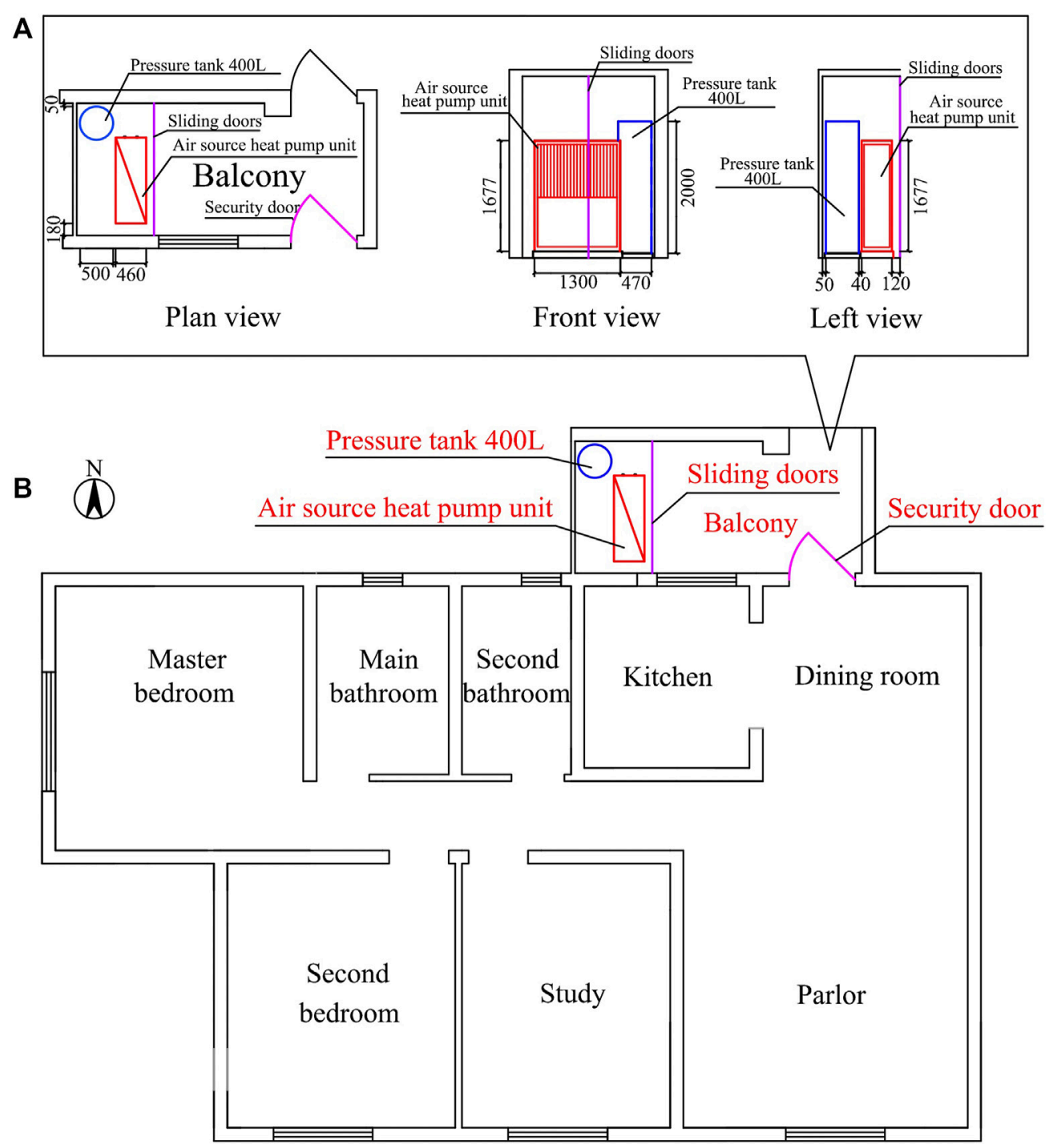

FIGURE 3 | The user plan and outdoor unit installation position in the balcony.

\section{RESULTS AND DISCUSSION}

\section{The COP Under Different Ventilation Conditions}

The COP under 7 conditions was studied experimentally in this paper. Under the results of the 7 conditions, Figures 6-12 respectively show the variations of the COP of the heating system and the outdoor air temperature variations under conditions 1 to 7 . The ventilation efficiency of the outdoor unit in condition 1 was the best because the sliding doors were completely removed and the security door was fully opened. The COP varied between 2.67 and 2.97 (average 2.86) during the test period and the outdoor temperature was stable between 7.10 and $7.60^{\circ} \mathrm{C}$ (average $7.40^{\circ} \mathrm{C}$ ). For condition 7 , the sliding door was pushed to the left (the right side is open) and the security door was closed. The COP varied from 2.19 to 2.74 (average 2.49) and the outdoor air temperature during the test was between 8.00 and $8.40^{\circ} \mathrm{C}$ (average $8.20^{\circ} \mathrm{C}$ ). The COP of condition 7 with higher outdoor temperature was significantly lower than condition 1, which indicated that the unfavorable ventilation conditions caused a negative impact on the heating performance of the heating system.

From condition 2 to condition 6 , the time starts and ends from $11: 36$ to $13: 00,13: 00$ to $13: 55,13: 55$ to $14: 40,14: 40$ to $15: 45$, and $15: 45$ to $17: 50$, respectively. The outdoor air temperature rises first and then decreases. The lowest temperature is $7.4^{\circ} \mathrm{C}$ at $11: 36$, and the highest temperature is $13.2^{\circ} \mathrm{C}$ at $15: 02$ in the afternoon. The heating coefficient of the main engine is different under different working conditions.

At condition 2, the average outdoor temperature was $8.5^{\circ} \mathrm{C}$, and the COP varied between 1.10 and 2.74 (average 2.57). In condition 3 , the average outdoor temperature was $10.4^{\circ} \mathrm{C}$, and the $\mathrm{COP}$ varied 


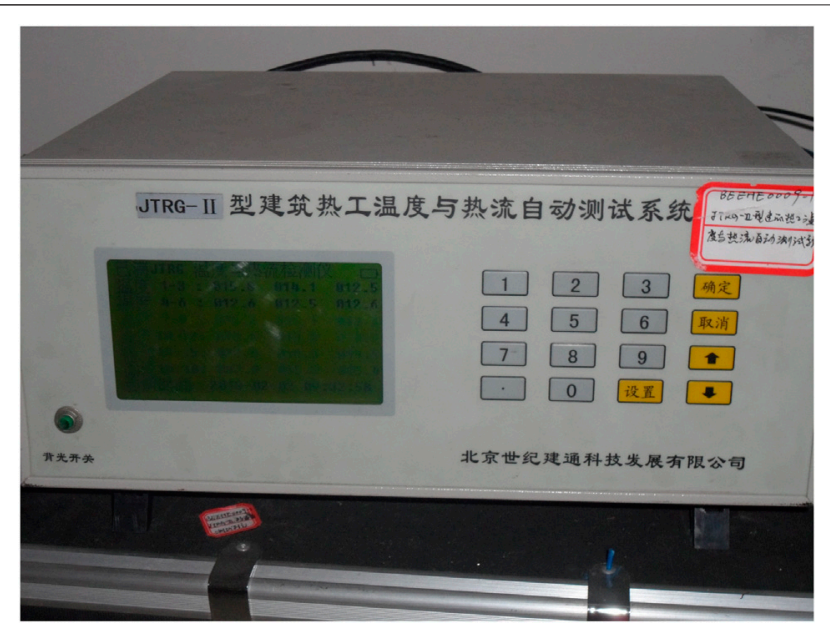

FIGURE 4 | JTRG-II automatic test system.

TABLE 1 | Test condition table of ventilation environment affecting the COP of heating.

\begin{tabular}{lccc} 
Number & $\begin{array}{c}\text { The left side } \\
\text { of sliding doors }\end{array}$ & $\begin{array}{c}\text { The right side } \\
\text { of sliding doors }\end{array}$ & Security door \\
\hline 1 & $\sqrt{ }$ & $\sqrt{ }$ & $\sqrt{ }$ \\
2 & $\times$ & $\sqrt{ }$ & $\sqrt{ }$ \\
3 & $\sqrt{ }$ & $\times$ & $\sqrt{ }$ \\
4 & $\sqrt{ }$ & $\sqrt{ }$ & $\times$ \\
5 & $\sqrt{ }$ & $\times$ & $\times$ \\
6 & $\times$ & $\times$ & $\times$ \\
7 & $\times$ & $\sqrt{ }$ & $\times$ \\
\hline
\end{tabular}

between 2.44 and 2.90 (average 2.79). In condition 4, the average outdoor temperature was $12^{\circ} \mathrm{C}$, and the COP varied between 2.36 and 2.83 (average 2.61). In condition 5, the average outdoor temperature was $12.4^{\circ} \mathrm{C}$, and the COP varied between 2.30 and 2.83 (average 2.52). In condition 6, the test time is longer, and there is a large difference between COP values before and after. The COP value of the heating performance coefficient of the main engine is small from 15:45 to 16:20 with an average value of 2.43 . The average

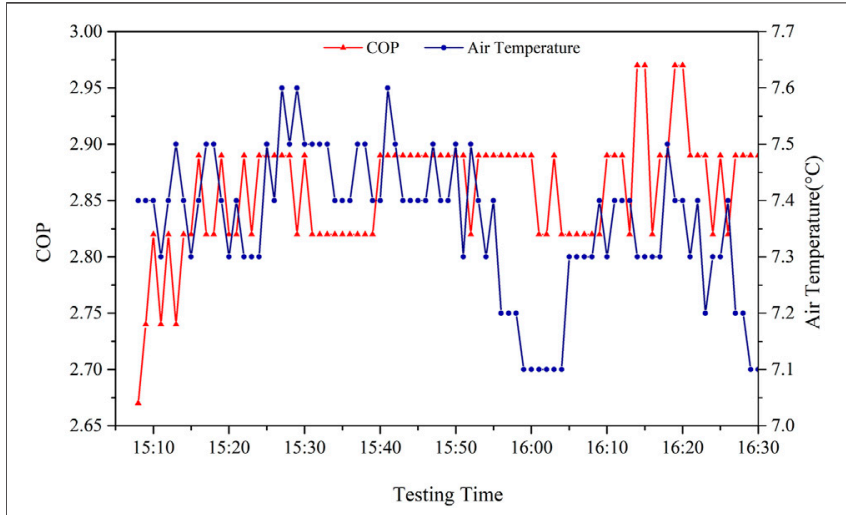

FIGURE 6 | The COP and outdoor air temperature in condition 1.

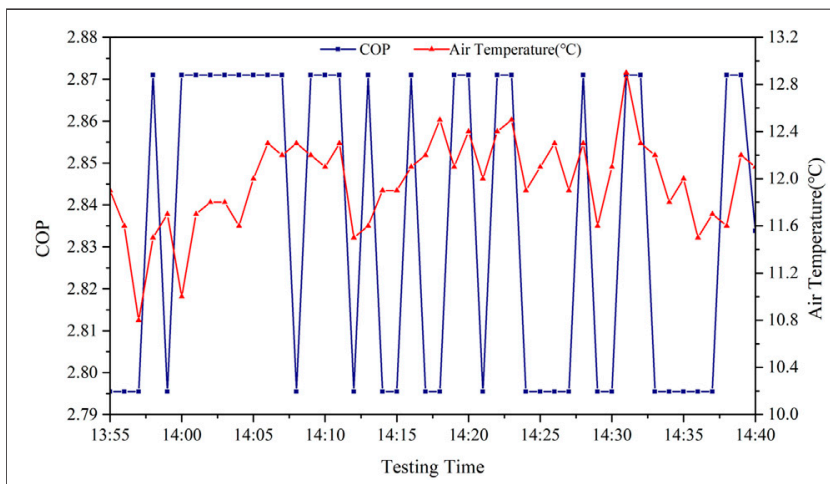

FIGURE 7 | The COP and outdoor air temperature in condition 2.

COP value reaches the lowest at $16: 20$ to $16: 40$, which is only 1.83 . Between 16:40 and 17:50, the COP value increased significantly, and the COP varied between 2.59 and 2.83 (average 2.75).

The outdoor temperature of condition 5 was $0.40^{\circ} \mathrm{C}$ higher than condition 7 . Since the heating performance of opening the left-side sliding door was preferable to the right side of the sliding door, the heating system COP increased by $3.20 \%$. Similarly, the outdoor air temperature in condition 6 was $0.40^{\circ} \mathrm{C}$ higher than in

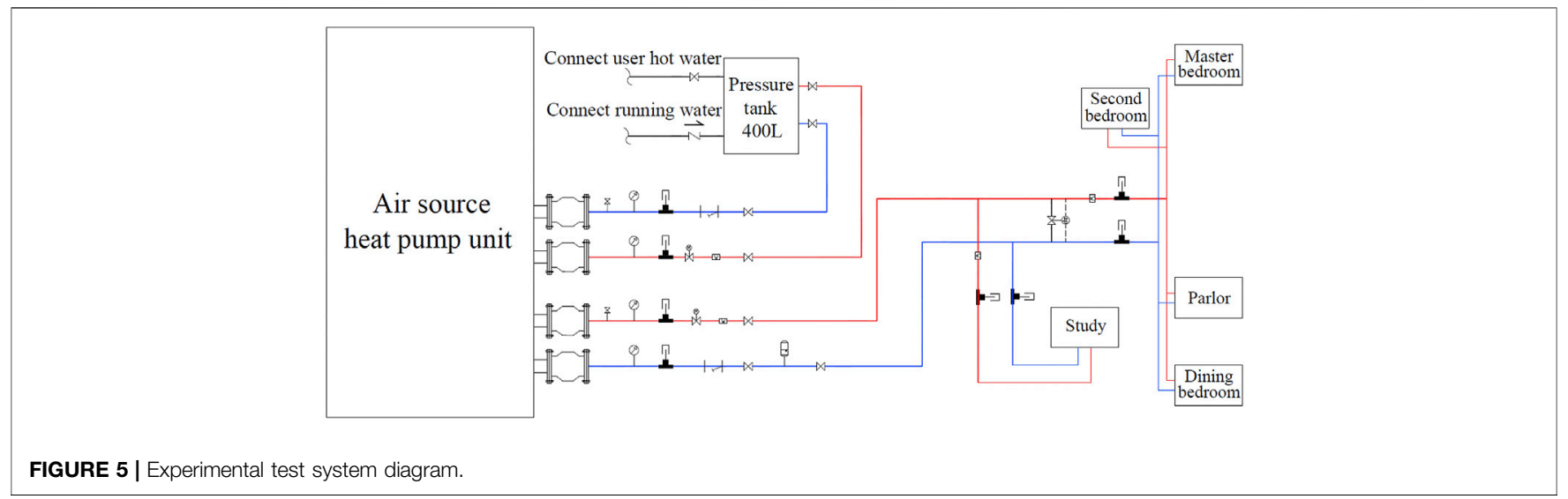




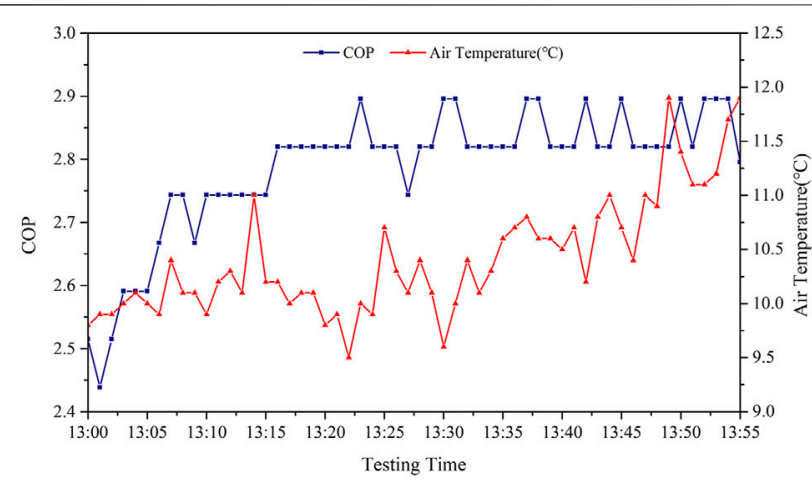

FIGURE 8 | The COP and outdoor air temperature in condition 3.

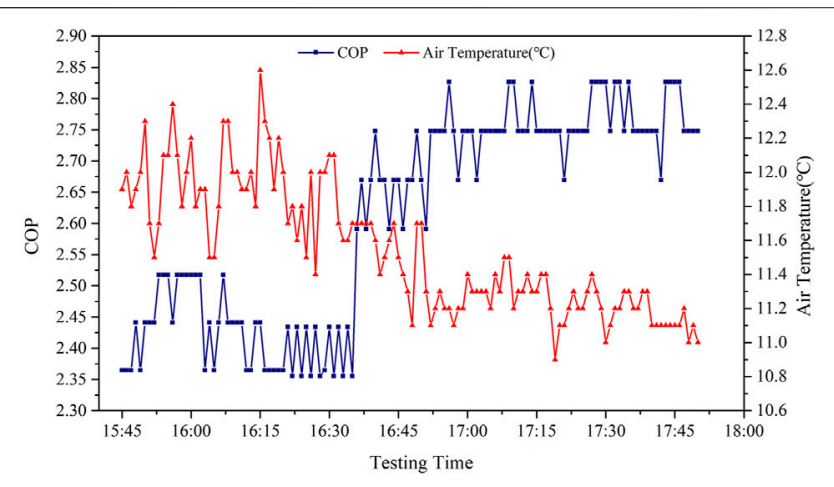

FIGURE 9 | The COP and outdoor air temperature in condition 4.

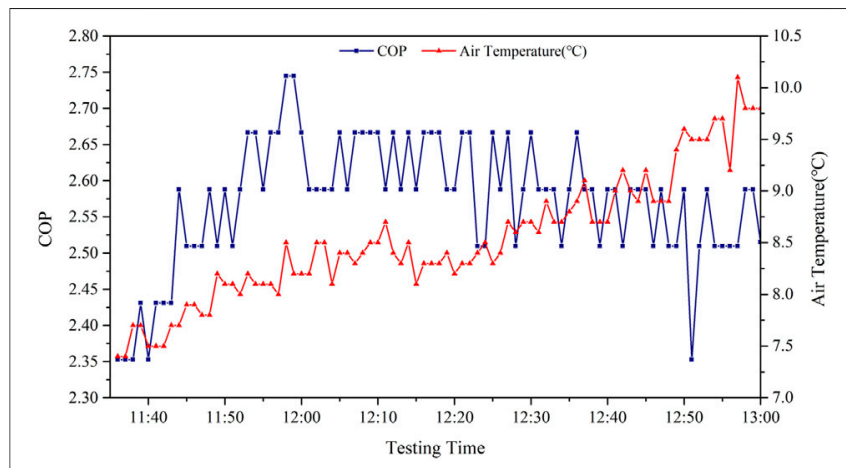

FIGURE 10 | The COP and outdoor air temperature in condition 5.

condition 2, but the COP under condition 6 was reduced by $11.00 \%$ due to the poor ventilation environment of condition 6 . It can be seen that the COP changes in the ASHP heating system were different when the outdoor temperature changed uniformly so that the influence of the ventilation environment on its heating performance cannot be ignored.

The heating performance coefficient of the main engine has a certain relationship with outdoor air temperature and generally

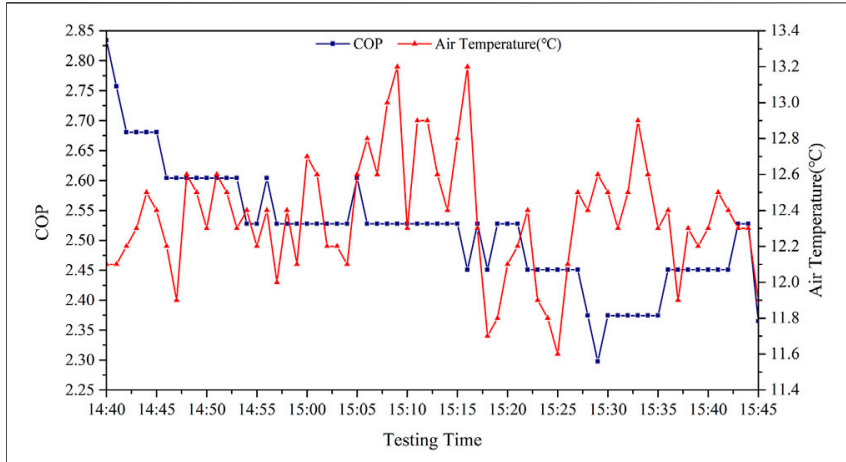

FIGURE 11 | The COP and outdoor air temperature in condition 6.

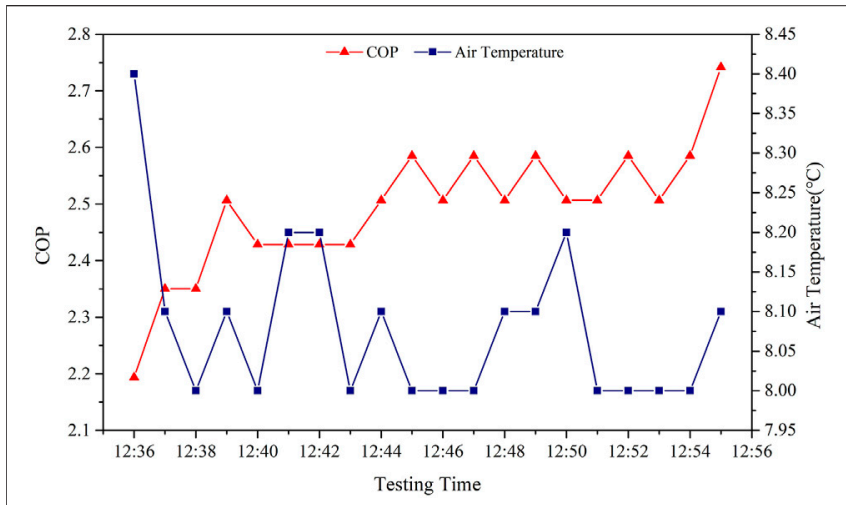

FIGURE 12 | The COP and outdoor air temperature in condition 7.

increases with the increase of air temperature. In this experiment, the COP value did not rise with the rise of the outdoor air. It is due to the experimental factors affecting the main COP value as host evaporator heat fin ventilation effect. The ventilation airflow organization has differences under different conditions which directly affect the heating performance of the host. At the beginning of working condition 6 , the reason for the low COP value is that the airflow in condition 5 is not well organized, which worsens the environment of heat exchange fin and leads to the frost of the main engine. The main engine automatically enters the defrost working condition and the COP value is the lowest at this time, even lower than 0 . The reason for this result is that the heat produced by the compressor enters the evaporator first when the defrosting is forced into the refrigeration condition. Then it enters the plate heat exchanger to exchange heat with the circulating water at the end. The return water temperature may be higher than the supply water temperature, and the temperature difference is less than 0 .

\section{The Average COP Under Different Ventilation Conditions}

Figure 13 shows the comparison of the average COP of the measured heating system under different conditions and the 


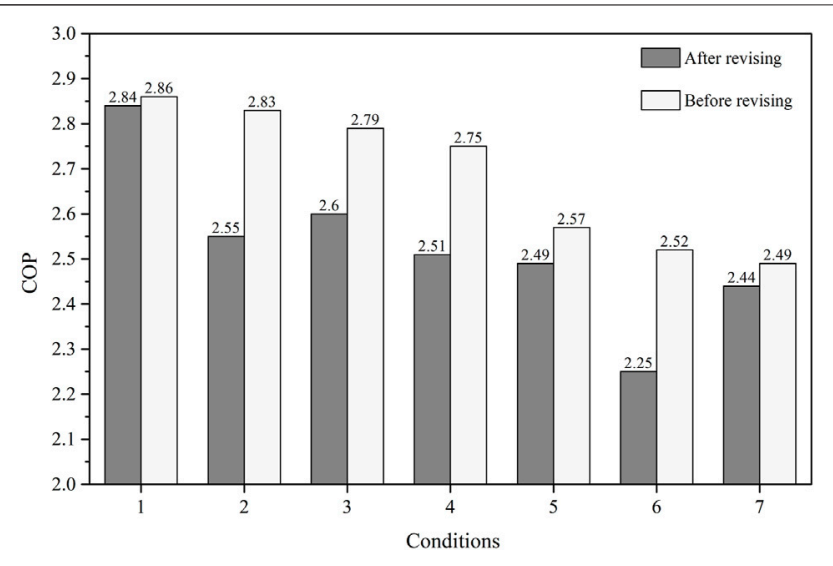

FIGURE 13 | Comparison of the average of the COP of the heating system under different conditions.

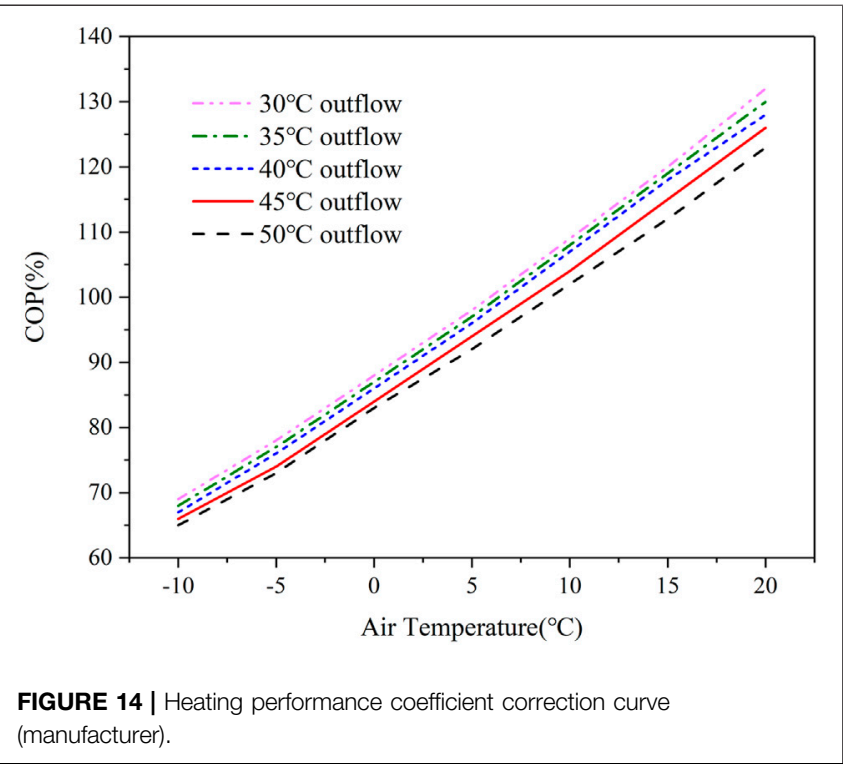

average outdoor air temperature. It can be seen that under the different ventilation conditions of the outdoor unit, the average COP of the measured heating system varied between 2.49 and 2.86 and the difference was clear. The test data showed that the ventilation conditions of the outdoor unit had a qualitative effect on the heating system. However, due to the limitations of experimental conditions, it is difficult to maintain the same ambient temperature of the altered ventilation conditions, so there is a certain difference in the outdoor air temperature for each condition.

\section{The Average COP With Air Temperature Revising}

Air temperature is one of the most important factors affecting the COP of the outdoor unit of the ASHP, but the outdoor air temperature under different conditions is different. Therefore,

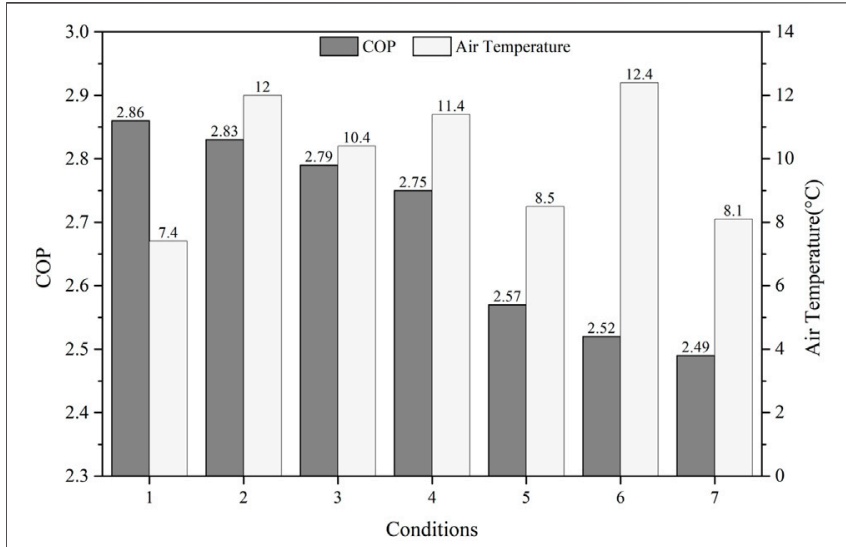

FIGURE 15 | System COP under different conditions after excluding the influence of the outdoor temperature.

the factors of the diverse outdoor temperatures must be excluded in order to analyze the influence of the outdoor unit ventilation conditions on the heating performance comprehensively. Figure 14 shows the variation curve of COP of an outdoor unit with the outdoor temperature at different outflow temperatures. COP increases by 0.02 while the outdoor air temperature increases by $1.00^{\circ} \mathrm{C}$.

The COP of the outdoor unit in the test was revised with the coefficient correction in Figure 11. Figure 15 presents the comparison of the COP before and after outdoor temperature correction under different conditions. It can be seen that: (1) When the security door was opened and the sliding doors were removed, the COP was 2.84 , which is higher by $20.80 \%$ than when the sliding doors were closed. (2) When the security door was opened and the right fan and left fan sliding door were opened, respectively, the COP was 2.55 and 2.60, respectively, which was 13.50 and $11.80 \%$ higher than the condition of the closed sliding door respectively. (3) The security door was closed, and the sliding doors were removed, and the COP of the heating system was 2.51 , which is $10.40 \%$ higher than when the sliding doors were closed. (4) The security doors were closed and the right and left fan sliding doors were opened, respectively, and the COP of the heating system was 2.44 and 2.49. The COP was increased by 0.19 and 0.24 , respectively, compared to the condition of closing the sliding doors, nearly 7.80 and $9.60 \%$. (5) When the security doors and sliding doors were closed, the COP of the heating system with the value of 2.25 was the lowest. The ventilation conditions of the outdoor unit have a significant influence on the COP of the heating system of the household ASHP system.

\section{CONCLUSION}

In this paper, experiments were taken to compare the COP of the heating system under different ventilation conditions of the outdoor unit. Results show that the ventilation environment has a great impact on the COP of the heating system. The 
COP of the heating system with better ventilation conditions could be $26.20 \%$ higher than the poor ventilation condition. The $\mathrm{COP}$ of the heating system is closely related to the ventilation conditions on the inlet side from the above experimental results. The following conclusions are obtained:

(1) When the sliding doors were closed, the distance between the inlet and the sliding doors was $12.00 \mathrm{~cm}$. The exhaust fan discharges air to the outdoor environment and the air inlet side absorbed the air by suction. The source of the wind turned into the outlet as the negative pressure side sliding doors closed, which caused the air distribution in the heating system to be disturbed and the airflow was short-circuited.

(2) The airflow resistance on the right side of the heating system was increased which increased the unfavorable factors of ventilation of the heat exchange ribs because of the bulky size of the tank. Therefore, the heating capacity of the heating system was the worst when the sliding doors were closed. If the heating system was operated for a long time, the air-flow environment would become worse which makes the heating system vulnerable to frost causing energy wastage and the start-stop frequency of the compressor.

(3) The heating performance of opening the left-side sliding door was preferable to the right side of the sliding door. Due to the relative position of the outdoor unit and the sliding doors, the parallel sliding door uncovered the heat exchanger fin area of opening the left fan was $820 \mathrm{~mm} \times 800 \mathrm{~mm}$, and opening the right fan was $480 \mathrm{~mm} \times 800 \mathrm{~mm}$. Therefore, the heating performance was good when the area of the rib was not covered.

(4) The effect of opening the home security door was better than not opening. The reason was that opening the home security door can effectively avoid the short circuit of the airflow and form cross-ventilation. In addition, the area of the vertical inlet of the heat exchange ribs increased to improve the air distribution.

(5) The outdoor air temperature had different effects on the COP under different ventilation conditions. The COP gradually increased while the outdoor temperature rises with excellent ventilation. In addition, the COP may gradually decrease as the outdoor temperature rises with inadequate ventilation conditions. The COP changes in the ASHP heating system were different when the outdoor temperature changed

\section{REFERENCES}

Bertsch, S. S., and Groll, E. A. (2008). Two-stage Air-Source Heat Pump for Residential Heating and Cooling Applications in Northern U.S. Climates. Int. J. Refrigeration 31 (7), 1282-1292. doi:10.1016/j.ijrefrig.2008.01.006

Busato, F., Lazzarin, R. M., and Noro, M. (2013). Two Years of Recorded Data for a Multisource Heat Pump System: a Performance Analysis. Appl. Therm. Eng. 57 (1-2), 39-47. doi:10.1016/j.applthermaleng.2013.03.053

Dongellini, M., Naldi, C., and Morini, G. L. (2015). Annual Performances of Reversible Air Source Heat Pumps for Space Conditioning. Energ. Proced. 78, 1123-1128. doi:10.1016/j.egypro.2015.11.070

Ge, F., Guo, X., Hu, Z., and Chu, Y. (2011). Energy Savings Potential of a Desiccant Assisted Hybrid Air Source Heat Pump System for Residential Building in Hot uniformly so that the influence of the ventilation environment on its heating performance cannot be ignored.

(6) Airflow around the ASHP outdoor units was very complex. The flow state can be simulated by using the flow dynamics method to obtain the optimal ventilation layout.

To sum up, reasonable space should be reserved for external machines in architectural design. Besides, the following points should be taken into consideration when carrying out system design: (a) The outdoor unit should be placed in a suitable environment for natural ventilation. (b) If the space is limited and the outdoor unit cannot be placed in a natural ventilation environment or outdoors, the obstruction of the outdoor unit fins by doors or objects should be minimized. (c)The air flow short circuiting of the outdoor unit can be effectively avoided by placing it where the crossventilation is adequate. The air flow around the ASHP unit is complicated. The next work is to use the computational flow dynamics method to simulate the air flow state to find the best ventilation layout.

\section{DATA AVAILABILITY STATEMENT}

The original contributions presented in the study are included in the article/Supplementary Material, further inquiries can be directed to the corresponding author.

\section{AUTHOR CONTRIBUTIONS}

Conceptualition, HZ; methodology, HZ; validation, EL and ZL; formal analysis, $\mathrm{HZ}$; investigation, $\mathrm{HZ}$; resources, $\mathrm{EL}$; data curation, HZ; writing-review and editing, $\mathrm{HZ}$ and EL; visualization, HZ; supervision, EL; project administration, EL; funding acquisition, EL All authors have read and agreed to the published version of the manuscript.

\section{FUNDING}

This work was supported by the National Natural Science Foundation of China (No. 52078314, No. 51778382).

Summer and Cold winter Zone in China. Energy and Buildings 43 (12), 3521-3527. doi:10.1016/j.enbuild.2011.09.021

Hakkaki-Fard, A., Aidoun, Z., and Ouzzane, M. (2014). Applying Refrigerant Mixtures with thermal glide in Cold Climate Air-Source Heat Pumps. Appl. Therm. Eng. 62 (2), 714-722. doi:10.1016/j.applthermaleng.2013.10.033

Hewitt, N., and Huang, M. J. (2008). Defrost Cycle Performance for a Circular Shape Evaporator Air Source Heat Pump. Int. J. Refrigeration 31 (3), 444-452. doi:10.1016/j.ijrefrig.2007.07.010

Jin, L., Cao, F., Yang, D., and Wang, X. (2016). Performance Investigations of an R404a Air-Source Heat Pump with an Internal Heat Exchanger for Residential Heating in Northern China. Int. J. Refrigeration 67, 239-248. doi:10.1016/j.ijrefrig.2016.03.004

Jing, Z., Nianping, L., Jianlin, C., Yang, Z., and Chen, W. (2016). Evaluation of the Sensible Heat Storage Air Source Heat Pump for Residential Heating in centralsouth China. Energ. Proced. 88, 703-708. doi:10.1016/j.egypro.2016.06.047 
Kelly, J. A., Fu, M., and Clinch, J. P. (2016). Residential home Heating: the Potential for Air Source Heat Pump Technologies as an Alternative to Solid and Liquid Fuels. Energy Policy 98, 431-442. doi:10.1016/ j.enpol.2016.09.016

Li, G. (2015). Comprehensive Investigations of Life Cycle Climate Performance of Packaged Air Source Heat Pumps for Residential Application. Renew. Sustainable Energ. Rev. 43, 702-710. doi:10.1016/ j.rser.2014.11.078

Liu, M., He, Y., Zhang, H., Su, H., and Zhang, Z. (2020). The Feasibility of Solar thermal-air Source Heat Pump Water Heaters in Renewable Energy Shortage Regions. Energy 197, 117189. doi:10.1016/j.energy.2020.117189

Madonna, F., and Bazzocchi, F. (2013). Annual Performances of Reversible Air-ToWater Heat Pumps in Small Residential Buildings. Energy and Buildings 65, 299-309. doi:10.1016/j.enbuild.2013.06.016

Redón, A., Navarro-Peris, E., Pitarch, M., Gonzálvez-Macia, J., and Corberán, J. M. (2014). Analysis and Optimization of Subcritical Two-Stage Vapor Injection Heat Pump Systems. Appl. Energ. 124, 231-240. doi:10.1016/ j.apenergy.2014.02.066

Touchie, M. F., and Pressnail, K. D. (2014). Evaluating a Proposed Retrofit Measure for a Multi-Unit Residential Building Which Uses an Air-Source Heat Pump Operating in an Enclosed Balcony Space. Energy and Buildings 85, 107-114. doi:10.1016/j.enbuild.2014.08.048

Vieira, A. S., Stewart, R. A., and Beal, C. D. (2015). Air Source Heat Pump Water Heaters in Residential Buildings in Australia: Identification of Key Performance Parameters. Energy and Buildings 91, 148-162. doi:10.1016/ j.enbuild.2015.01.041

Vocale, P., Morini, G. L., and Spiga, M. (2014). Influence of Outdoor Air Conditions on the Air Source Heat Pumps Performance. Energ. Proced. 45, 653-662. doi:10.1016/j.egypro.2014.01.070

Wu, W., Shi, W., Wang, B., and Li, X. (2013). A New Heating System Based on Coupled Air Source Absorption Heat Pump for Cold Regions: Energy Saving Analysis. Energ. Convers. Management 76, 811-817. doi:10.1016/ j.enconman.2013.08.036
Zhang, Q., Zhang, L., Nie, J., and Li, Y. (2017). Techno-economic Analysis of Air Source Heat Pump Applied for Space Heating in Northern China. Appl. Energ. 207, 533-542. doi:10.1016/j.apenergy.2017.06.083

Zhang, Y., Long, E., Zhao, X., Jin, Z., Liu, Q., Liang, F., et al. (2017). Combined Solar Heating and Air-Source Heat Pump System with Energy Storage: thermal Performance Analysis and Optimization[J]. Proced. Eng. 205, 4090-4097. doi:10.1016/j.proeng.2017.09.896

Zhao, J., Chen, Y., Qu, H., and Li, X. (2007). Operation Performance of Air Source Heat Pump System for Space Heating in Tianjin. Trans. Tianjin Univ. 13 (2), 137-141.

Zhao, X., Long, E., Zhang, Y., Liu, Q., Jin, Z., and Liang, F. (2017). Experimental Study on Heating Performance of Air - Source Heat Pump with Water Tank for Thermal Energy Storage. Proced. Eng. 205, 2055-2062. doi:10.1016/ j.proeng.2017.10.087

Conflict of Interest: Authors HZ and ZL were employed by the China Construction First Group.

The remaining author declares that the research was conducted in the absence of any commercial or financial relationships that could be construed as a potential conflict of interest.

Publisher's Note: All claims expressed in this article are solely those of the authors and do not necessarily represent those of their affiliated organizations, or those of the publisher, the editors, and the reviewers. Any product that may be evaluated in this article, or claim that may be made by its manufacturer, is not guaranteed or endorsed by the publisher.

Copyright $(2021$ Zou, Liu and Long. This is an open-access article distributed under the terms of the Creative Commons Attribution License (CC BY). The use, distribution or reproduction in other forums is permitted, provided the original author(s) and the copyright owner(s) are credited and that the original publication in this journal is cited, in accordance with accepted academic practice. No use, distribution or reproduction is permitted which does not comply with these terms. 